\title{
Rupture extent of the 1938 Alaskan earthquake as inferred from tsunami waveforms
}

\author{
Jean M. Johnson and Kenji Satake \\ Department of Geological Sciences, University of Michigan
}

\begin{abstract}
Using tsunami waveforms, we estimate the source parameters of the 10 November 1938 Alaskan earthquake. The earthquake ruptured a 300-km-long segment of the Alaskan arc, which corresponds to the aftershock area. The seismic moment is approximately $20 \times 10^{20} \mathrm{Nm}$, or $M_{w}=8.2$, and the moment release was concentrated in the eastern end of the aftershock zone. The tsunami and seismic evidence strongly suggest that the 1938 earthquake did not rupture into the Shumagin Islands gap.
\end{abstract}

\section{Introduction}

The Shumagin Islands seismic gap is a segment of the Alaskan-Aleutian arc that has not ruptured in a great earthquake this century [Davies et al., 1981] and accordingly may have a high seismic potential. The Shumagin Islands gap is bounded to the west by the rupture area of the 1 April 1946 Aleutian earthquake and to the east by the 10 November 1938 Alaskan earthquake (Figure 1). However, the rupture area of the 1938 earthquake is not well known; therefore, it is difficult to define the length of the Shumagin Islands gap.

The 1938 earthquake $\left(M_{2}=8.3\right.$, from Gutenberg and Richter, 1954) occurred off the Alaska Peninsula at $55.2^{\circ} \mathrm{N}, 158.5^{\circ} \mathrm{W}$ at 20:18 G.M.T. and was felt from Unimak Island, at the end of the Alaskan Peninsula, to Anchorage, Alaska. Basic source parameters such as rupture area, slip distribution, and seismic moment are not well known because the earthquake occurred in a sparsely populated area and little high-quality seismic data are available. We must determine the rupture length of the 1938 Alaskan earthquake if the length of the Shumagin Islands gap is to be determined and the seismic potential in this area accurately assessed.

\section{Previous Studies of the 1938 Earthquake}

Sykes [1971] relocated the aftershocks of the 1938 earthquake and found that it was difficult to define the aftershock zone. Two "aftershocks" occurred 100 and $200 \mathrm{~km}$ west of the mainshock in the Shumagin Islands gap; however, as these earthquakes were deeper than any of the other aftershocks, Sykes concluded that they were not a part of the aftershock sequence, but occurred in the downgoing Pacific Plate. From the other aftershocks, Sykes estimated the length of rupture as approximately $300 \mathrm{~km}$. Davies et al. [1981] also relocated the aftershocks of the 1938 event and could not determine the aftershock zone any more precisely than Sykes. Using the relationship between rupture length and seismic moment [Kanamori, 1977], Davies et al. concluded that a $300 \mathrm{~km}$

Copyright 1994 by the American Geophysical Union.

Paper number 94GL00333

0094-8534/94/94GL-00333\$03.00 rupture length was consistent with the estimate of the moment derived from long-period mantle waves [Brune and Engen, 1969]. Davies et al. could not find any seismic evidence that the 1938 earthquake had ruptured into the Shumagin Islands gap.

Both Davies et al. and Hatori [1981] estimated the length of rupture based on backward propagation of the tsunami from tide gauges. However, their estimates disagree. Davies et al. estimated a rupture length of $300 \mathrm{~km}$. Hatori included several tide gauge records from Japan and estimated the length as $400 \mathrm{~km}$, which included the eastern portion of the Shumagin gap. Through examination of the original records, we found that the data quality of the Japanese tide gauge records is in some cases very poor, so Hatori's estimate may be unreliable.

Like the rupture length, the seismic moment of the 1938 earthquake is not well determined. Moment estimates have mainly been based on magnitude estimates. Gutenberg and Richter [1954] determined the magnitude as $M_{\mathbf{g}}=8.3$. Brune and Engen [1969] used the 100-sec mantle waves to estimate the magnitude as $M_{M}=8.3$. Using the 100 -sec mantle waves and the size of the aftershock zone, Kanamori [1977] estimated the moment magnitude as $\mathbf{M}_{W}=8.2$. Abe [1979] assigned a magnitude of $\mathrm{M}_{\mathrm{t}}=8.3$ based on the maximum tsunami wave amplitudes observed on tide gauge records. Okal [1992] gives a mantle wave magnitude of $M_{m}=8.6$. These magnitudes give moment estimates of 12 to $40 \times 10^{20} \mathrm{Nm}$ (Table 1). But none of these estimates come from a direct determination of the seismic moment. Recently, Estabrook et al. [1994] inverted the available body and surface waves to determine the source time function and the moment distribution. They found that the rupture process could be described as two point sources, one at the epicenter and another approximately $180 \mathrm{~km}$ to the northwest. They estimated the moment as $37 \times 10^{20} \mathrm{Nm}$, or $M_{w}=8.3$.

\section{Tsunami Waveform Inversion}

The 1938 earthquake generated a Pacific-wide tsunami which was recorded on tide gauges in Alaska, N. America, Hawaii, and Japan. We use the tsunami waveforms to estimate the source area and slip distribution of the 1938 earthquake. This gives an additional, direct, estimate of the seismic moment. More importantly, our estimate of the source area provides an independent constraint on the eastern end of the Shumagin Islands gap.

Five tsunami waveforms from the 1938 earthquake were previously published [Neumann, 1940]. These are from Unalaska, Seward, and Sitka, AK; Santa Monica, CA, and Honolulu, HI. We obtained the original marigrams from NOAA and discovered three previously unpublished records: Crescent City, San Francisco, and San Diego, CA. Several marigrams from Japan were available, but the signal-to-noise ratio was poor, so we did not attempt to use them. We digitized the original records and applied clock corrections where necessary. The Seward tide gauge was not operating at the time of the first tsunami wave 


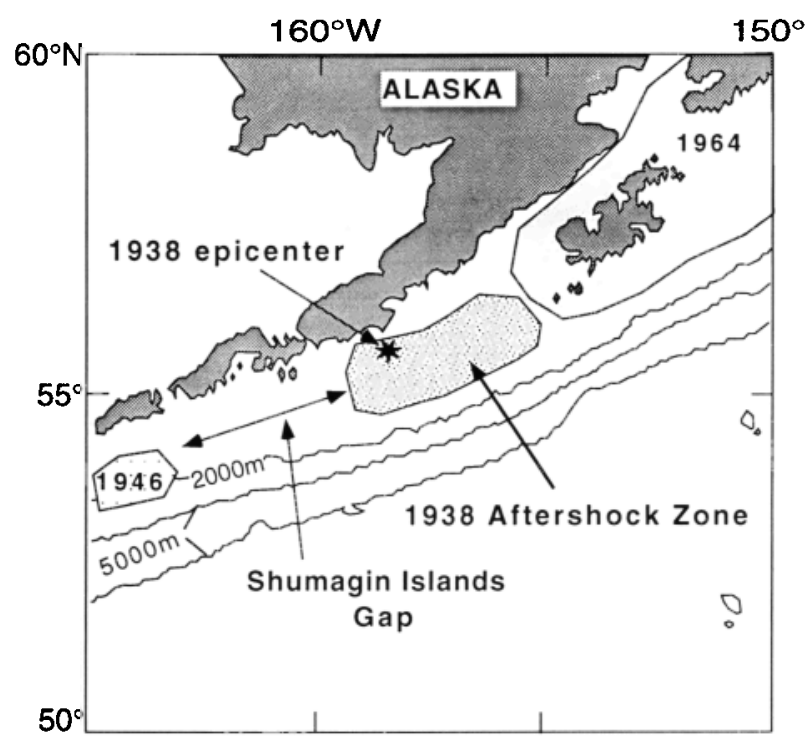

Figure 1. Aftershock area of the 1938 Alaskan earthquake and the Shumagin Islands seismic gap. Also shown are the aftershock areas of the 1946 Aleutian and 1964 Alaskan earthquakes.

arrival, so the record is incomplete and could not be used. Figure 2 shows the unfiltered, digitized marigrams of the unpublished tide gauge records. We removed the tidal component by using a moving average filter with a 1 hour time window.

We performed tsunami waveform inversion using the same method outlined in Johnson and Satake [1993]. We divided the 1938 aftershock zone into 3 subfaults. We also included an additional subfault in the Shumagin Islands area to determine whether we could resolve any slip past the western end of the aftershock zone. Figure 3 shows the locations of the subfaults. The fault parameters were the same for each subfault: length $\mathbf{1 0 0}$ $\mathrm{km}$, width $150 \mathrm{~km}$, dip $10^{\circ}$, and depth to the top of each subfault $20 \mathrm{~km}$ based on the depth to the upper boundary of the Pacific plate [Zhao et al., 1994]. Each subfault has unit displacement in the direction of $\mathrm{N}^{\circ} 5^{\circ} \mathrm{W}$, which is the direction of motion of the Pacific plate relative to North America [DeMets et al., 1990]. No focal mechanism is available for this earthquake [Okal, 1992],

Table 1: Magnitude estimates of the 1938 Alaskan earthquake

\begin{tabular}{|c|c|c|c|}
\hline & \multicolumn{2}{|c|}{ Magnitude } & \multirow{2}{*}{$\begin{array}{l}\text { Moment } \\
10^{20} \mathrm{Nm} \\
32\end{array}$} \\
\hline Richter [1954] & $\mathrm{M}_{\mathrm{s}}$ & 8.3 & \\
\hline $\begin{array}{l}\text { Brune and Engen } \\
\text { [1969] }\end{array}$ & $\mathbf{M}_{\mathbf{M}}$ & 8.3 & 12 \\
\hline Kanamori [1977] & $\mathbf{M}_{\mathbf{w}}$ & 8.2 & 28 \\
\hline Abe [1979] & $\mathbf{M}_{\mathbf{l}}$ & 8.3 & 32 \\
\hline Okal [1992] & $\mathbf{M}_{\mathrm{m}}$ & 8.6 & 40 \\
\hline $\begin{array}{l}\text { Estabrook et } \\
\text { al. [1994] }\end{array}$ & $\mathbf{M}_{\mathbf{w}}$ & 8.3 & 37 \\
\hline This study & $\mathbf{M}_{\mathbf{w}}$ & 8.2 & 20 \\
\hline
\end{tabular}
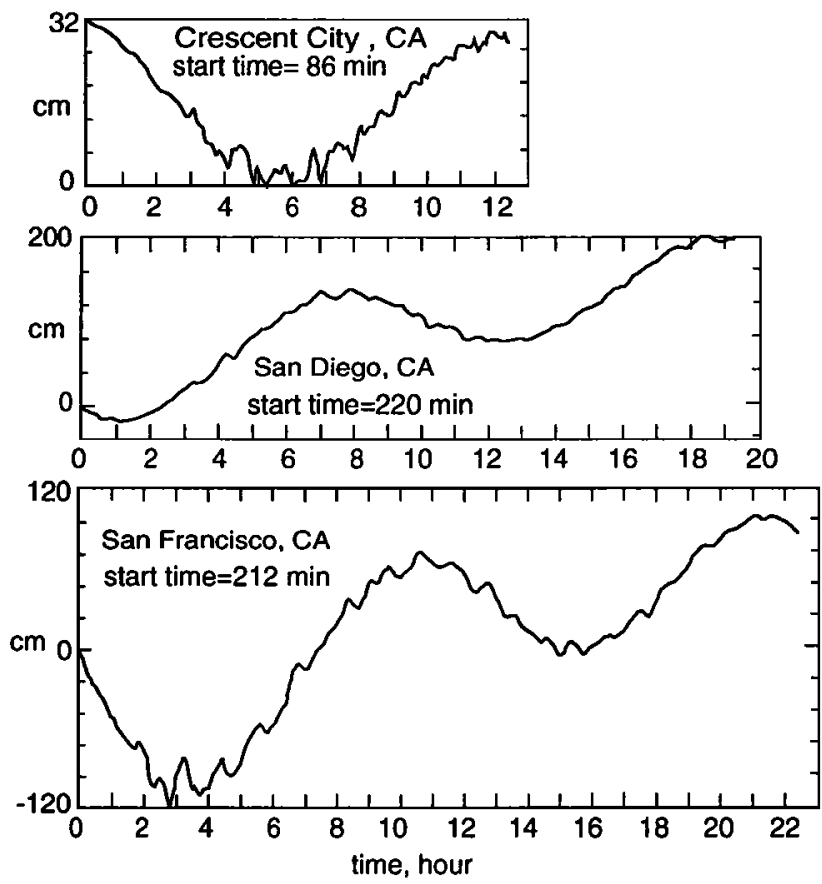

Figure 2. Digitized marigrams from 1938 Alaskan earthquake recorded in Crescent City, San Diego, and San Francisco. The tidal component has not been removed. Start time listed for each record is the time in minutes from the origin time of the earthquake to the start time of the digitized record.

but this slip vector is approximately arc-normal, which is similar to earthquakes observed in this region (for example, see Dziewonski et al., [1987]).

We inverted waveforms from six tide gauges: Unalaska, Sitka, San Francisco, Santa Monica, San Diego, and Honolulu. The waveform data consists of an average of 105 data points with a time interval of 1 min for each waveform, giving a total of 640 data points. Figure 4 shows the computed and observed waveforms. The arrows show which portion of the waveform used in the inversion. The reliability of the Green's functions

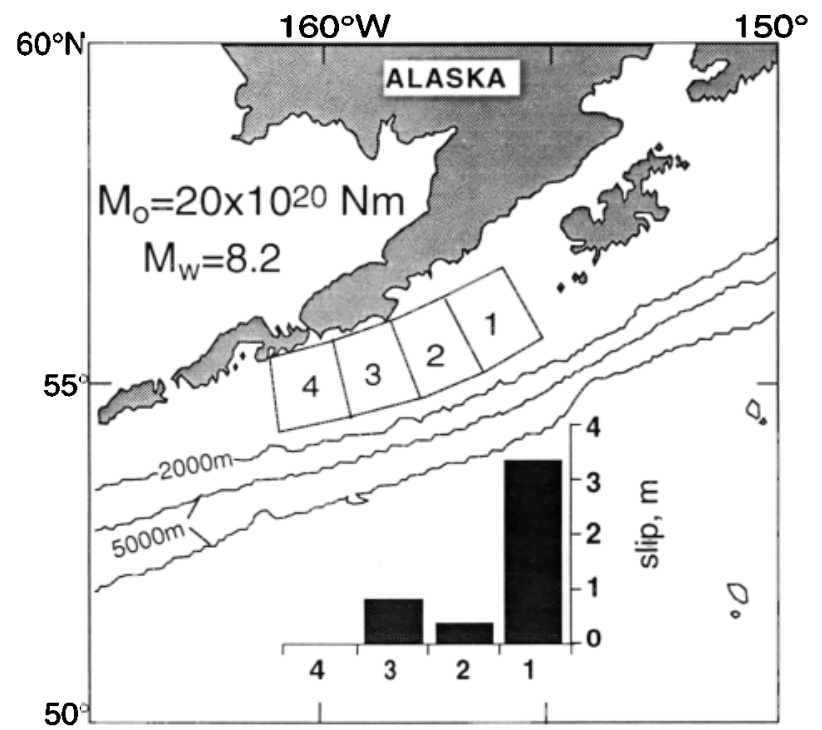

Figure 3. Location of subfaults used in inversion of tsunami waveforms. Graph shows slip distribution in meters. 
decreases with time, so we used only the first few pulses of each record for the inversion. However, as can be seen, the synthetic waveform matches the observed for several hours after the first arrival for some of the stations.

Both observation [Lander and Lockridge, 1989] and numerical modeling of tsunamis [Bernard et al., 1993] has shown that tsunami waves arriving at Crescent City are unusually large due to very local effects; therefore, we did not include the Crescent City waveform in the inversion. Despite this, Figure 4 shows that the phase and the approximate amplitude of the Crescent City record are matched using our results.

The slip distribution for the 1938 earthquake is given in Figure 3 and Table 2. The highest slip is on subfault $1(3.3 \mathrm{~m})$. Subfault 2 and 3 have less than 1 meter of slip. There is no slip on subfault 4 in the Shumagin Islands area. The slip distribution gives an average slip on the fault of $1.1 \mathrm{~m}$ and a seismic moment estimate of $20 \times 10^{20} \mathrm{Nm}$, or $\mathrm{M}_{\mathrm{W}}=8.2$.

We estimated the errors by a jackknife technique [Tichelaar and Ruff, 1989] in which one waveform is dropped from the data set and the remaining waveforms are inverted for the slip distribution. Six jackknife inversions were performed and the errors were estimated. These are also listed in Table 2. The errors show that the slip distribution may not be completely reliable, as the only significantly nonzero slip is on subfault 1 .

We also performed an inversion for the moment only on a single fault $300 \mathrm{~km}$ long. The slip amount was $2.1 \mathrm{~m}$, giving a moment of $25 \times 10^{20} \mathrm{Nm}$. This estimate of the moment is similar to the value from four subfaults, showing that the moment estimate is fairly stable, although the details of the slip distribution are not.

Our estimate of the moment of the 1938 earthquake is in good agreement with several of the previous estimates of the magnitude. The slip distribution obtained from tsunami waveform inversion agrees with the moment release estimate of Estabrook et al. [1994], which also found the greatest moment release to occur in the eastern end of the aftershock zone. The moment estimate from tsunami waveform inversion is smaller though, by about $40 \%$.

\section{Conclusions}

From our study of the tsunami records, we can now estimate reliably the source parameters of the 1938 Alaskan earthquake.

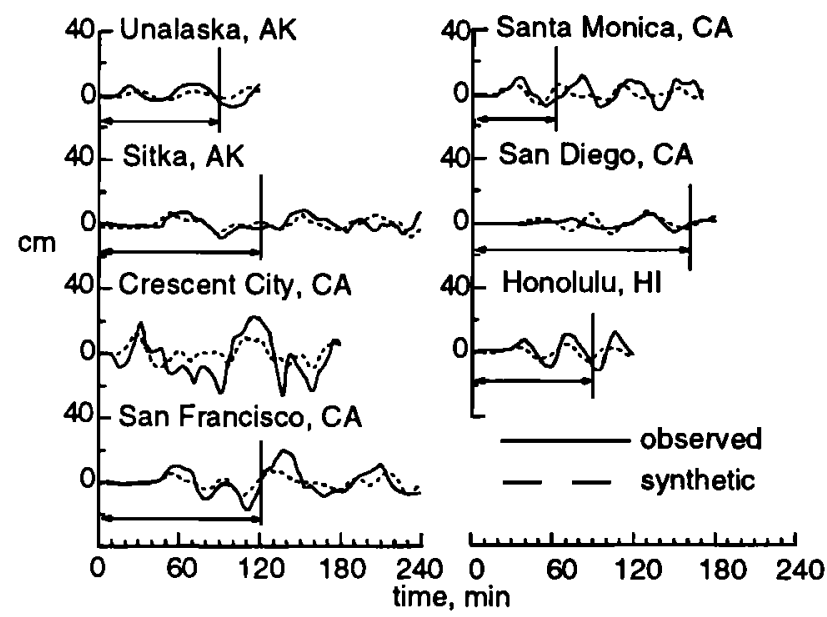

Figure 4. Observed and synthetic waveforms from inversion for four subfaults. Start time of each record is different. The arrows indicate the parts of the waveforms used for the inversion.
Table 2: Inversion results for 4 subfaults

\begin{tabular}{lll}
\hline & & \\
subfault \# & slip, m & error, $\mathbf{m}$ \\
\hline & & \\
\hline & 3.3 & 1.80 \\
3 & 0.34 & 1.84 \\
4 & 0.79 & 1.66 \\
& -0.01 & 1.08 \\
RMS error, m & & \\
average slip, m & & 0.0344 \\
M $_{\text {o. } 10^{20} \mathrm{Nm}}$ & & 1.1 \\
\hline
\end{tabular}

The earthquake ruptured a $300-\mathrm{km}$-long segment of the Alaskan arc. This corresponds to the aftershock area. The seismic moment is approximately $20 \times 10^{20} \mathrm{Nm}\left(\mathrm{M}_{\mathrm{W}}=8.2\right)$ and the moment release was concentrated in the eastern end of the aftershock zone. The slip distribution from tsunamis, taken with the seismic evidence, strongly suggests that the 1938 earthquake did not rupture into the Shumagin Islands gap.

Acknowledgements. We wish to thank J. Hubbard of Datums Section, NOAA for providing us with the original marigrams for the 1938 earthquake. This work was supported by U.S. Geological Survey grant 1434-93-G-2320.

\section{References}

Abe, K., Size of great earthquakes of 1873-1974 inferred from tsunami data, J. Geophys. Res., 84, 1561-1568, 1979.

Bernard, E.N., F.I. Gonzalez, and K. Satake, The Cape Mendocino tsunami, 25 April 1992, in Proc. Intemational Tsunami Symposium, Wakayama, Japan, 461-467, 1993.

Brune, J.N., and G.R. Engen, Excitation of mantle Love waves and definition of mantle wave magnitude, Bull. Seism. Soc. Am., 59, 923 934, 1969.

Davies, J., L. Sykes, L. House, and K. Jacob, Shumagin seismic gap, Alaska peninsula: history of great earthquakes, tectonic setting, and evidence for high seismic potential, J. Geophys. Res., 86, 3821-3855, 1981.

DeMets, C., R.G. Gordon, D.F. Argus, and S. Stein, Current plate motions, Geophys. J. Int., 101, 425-478, 1990.

Dziewonski, A.M., G. Ekström, J.E. Franzen, J.H. Woodhouse, Global seismicity of 1977; centroid-moment tensor solutions for 471 earthquakes, Phys. Earth Planet. Inter.,45, 11-36, 1987.

Estabrook, C.H., K.H. Jacob, and L.R. Sykes, Body wave and surface wave analysis of large and great earthquakes along the Eastern Aleutian Arc, 1923-1993: Implications for future events, J. Geophys. Res., in press, 1994.

Gutenberg, B., and C.F. Richter, Seismicity of the Earth and Associated Phenomena, 310 p, Hafner Publishing Co., 1954.

Hatori, T., Tsunami magnitude and source area of the Aleutian-Alaska tsunamis, Bull. Earthq. Res. Inst., Univ. of Tokyo, 56, 97-110, 1981.

Johnson, J.M., and K. Satake, Source parameters of the 1957 Aleutian earthquake from tsunami waveforms, Geophys. Res. Lett., 20, 1487$1490,1993$.

Kanamori, H., The energy release in great earthquakes, J. Geophys. Res., 82, 2981-2987, 1977.

Lander, J.F., and P.A. Lockridge, United States Tsunamis (including United States Possessions) 1690-1988, 265 pp, National Geophysical Data Center, 1989. 
Neumann, F., United States earthquakes 1938, 59 p, U.S. Department of Commerce Coast and Geodetic Survey, 1940.

Okal, E.A., Use of mantle magnitude $M_{m}$ for the reassessment of the moment of historical earthquakes I: Shallow events, Pure Appl. Geophys., 139, 17-57, 1992.

Sykes, L., Aftershock zones of great earthquakes, seismicity gaps, and earthquake predicion for Alaska and the Aleutians, J. Geophys. Res., 76, 8021-8041, 1971.

Tichelaar, B.W., and L.J. Ruff, How good are our best models?
Jackknifing, bootstrapping, and earthquake depth, EOS, 70, 593, 605606, 1989.

Zhao, D., D. Christensen, and H. Pulpan, Tomographic imaging of the Alaskan subduction zone, submitted to J. Geophys. Res., 1994.

J.M. Johnson and K. Satake, Dept. of Geological Sciences, Univ. of Michigan, Ann Arbor, MI 48109-1063.

(Received: August 17, 1993; accepted October 13, 1993.) 